Disclosure of Interest: None declared

DOI: 10.1136/annrheumdis-2017-eular.1611

\section{AB1111 A PROSPECTIVE COHORT STUDY MEASURING COST-BENEFIT ANALYSIS OF THE OTAGO EXERCISE PROGRAMME IN COMMUNITY DWELLING ADULTS WITH RHEUMATOID ARTHRITIS}

S. Abdulrazaq ${ }^{1}$, T. O'Neill ${ }^{2}$, E.K. Stanmore ${ }^{3}$, J. Oldham ${ }^{1}$, D. Skelton ${ }^{4}$, M. Pilling ${ }^{5}$, B. Gannon ${ }^{1}$, C. Toddd ${ }^{1}{ }^{1}$ School of Nursing, Midwifery and Social Work and MAHSC; ${ }^{2}$ School of Medical Sciences; ${ }^{3}$ School of Nursing, University of Manchester, Manchester; ${ }^{4}$ University of Glasgow, Glasgow; ${ }^{5}$ University of Manchester, Manchester, United Kingdom

Background: Falls are one of the major health problems in adults with Rheumatoid Arthritis (RA). Interventions, such as the Otago Exercise Programme (OEP), can reduce falls in community dwelling adults by up to $35 \%$. The cost-benefits of such a programme in adults with RA have not been studied

Objectives: To determine healthcare cost of falls in adults with RA, and estimate whether it may be cost efficient to roll out the OEP to improve function and prevent falls in adults living with RA.

Methods: Patients with Rheumatoid Arthritis aged $\geq 18$ years were recruited from four rheumatology clinics across the Northwest of England. Participants were followed up for 1 year with monthly fall calendars, telephone calls and self-report questionnaires. Estimated medical cost of a fall-related injury incurred per-person were calculated and compared with OEP implemention costs to establish potential economic benefits.

Results: 535 patients were recruited and 598 falls were reported by 195 patients. Cumulative medical costs resulting from all injury leading to hospital services is $£ 374,354$ (US\$540,485). Average estimated cost per fall is $£ 1120$ (US\$1617). Estimated cost of implementing the OEP for 535 people is $£ 116,479$ (US\$168,504) or $£ 217.72$ (US\$314.34) per-person. Based on effectiveness of the OEP it can be estimated that out of the 598 falls, 209 falls would be prevented. This suggests that $£ 234,583$ (US $\$ 338,116$ ) savings could be made, a net benefit of $£ 118,104$ (US $\$ 170,623)$.

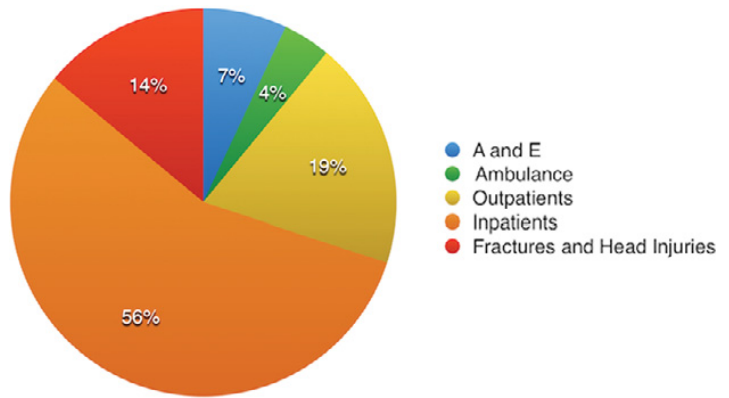

Figure 2. Chart showing spread of cost in health care costs

Conclusions: Implementation of the OEP programme for patients with RA has potentially significant economic benefits and should be considered for patients with the disease.

\section{References:}

[1] Stanmore EK, Oldham J, Skelton DA, O'Neill T, Pilling M, Campbell AJ, et al. Fall incidence and outcomes of falls in a prospective study of adults with rheumatoid arthritis. Arthritis Care Res (Hoboken). 2013;65(5):737-44.

[2] Stanmore EK, Oldham J, Skelton DA, O'Neill T, Pilling M, Campbell AJ, et al. Risk factors for falls in adults with rheumatoid arthritis: a prospective study. Arthritis Care Res (Hoboken). 2013:65(8):1251-8.

[3] Hayashibara M, Hagino H, Katagiri H, Okano T, Okada J, Teshima R. Incidence and risk factors of falling in ambulatory patients with rheumatoid arthritis: a prospective 1-year study. Osteoporos Int. 2010;21(11):1825-33.

[4] Gillespie LD, Robertson MC, Gillespie WJ, Sherrington C, Gates S, Clemson $\mathrm{LM}$, et al. Interventions for preventing falls in older people living in the community. Cochrane Database Syst Rev. 2012;9:CD007146.

[5] Gardner MM, Robertson MC, Campbell AJ. Exercise in preventing falls and fall related injuries in older people: a review of randomised controlled trials. British Journal of Sports Medicine. 2000;34(1):7-17.

[6] Robertson MC, Campbell AJ, Gardner MM, Devlin N. Preventing injuries in older people by preventing falls: a meta-analysis of individual-level data. J Am Geriatr Soc. 2002;50(5):905-11.

Acknowledgements: Special thanks to all the participants involved in the research and also the nursing staff who supported the data collection phase of the study at Manchester Academic Health Science Centre (MAHSC).

Disclosure of Interest: None declared

DOI: 10.1136/annrheumdis-2017-eular.1439

\section{AB1112 DATANETWORK RHEUMA 4.0 - REAL WORLD DATA FROM PRIVATE PRACTICE}

S. Kleinert ${ }^{1}$, F. Schuch ${ }^{1}$, S. Späthling-Mestekemper ${ }^{2}$, M. Feuchtenberger ${ }^{3}$, C. Kuhn ${ }^{4}$, M. Welcker ${ }^{5}$. ${ }^{1}$ Rheumatologie, Rheumatologische Schwerpunktpraxis, Erlangen; ${ }^{2}$ Rheumatologie, Rheumapraxis München-Pasing, München;

${ }^{3}$ Rheumatologie, Schwerpunktpraxis für Rheumatologie, Burghausen;

${ }^{4}$ Rheumatologie, Internistische Schwerpunktpraxis am Ludwigsplatz, Karlsruhe;

${ }^{5}$ Rheumatologie, MVZ für Rheumatologie Dr. Martin Welcker, Planegg, Germany

Background: The datanetwork Rheuma 4.0 (DNR_4.0) is a consortium of 5 internistic-rheumatologic specialized practices. Patient data that were collected routinely will be pooled pseudonymized (e.g. via RheumaDok) and will be made available to answer numerous healthcare- and scientific research questions.

Methods: The participating centres document the following data in specific rheumatologic data documentation systems (RheumaDok, Emil, DocuMed.rh). These data will be routed automatically to the data base of the DNR_4.0 via a prespecified interface and can be used for certain research areas:

Diagnosis (by rheumatologist $(R)$, anamnesis $(R)$, medication $(R)$, morning stiffness $(R$, patient $(P))$, scores like RADAI $(R, P)$, DAS28 (R), BASDAI (P), BASFI $(P)$, quality of life $(R, P)$. Also prespecified laboratory measures $(R)$ like ESR, CRP etc. can be collected automatically.

Patient reported Outcomes (PROs) that were entered via mobile applications like RheumaLive and AxSpALive can be collected in certain intervalls and be sent encrypted into the medical office data base.

The data entered by patients will be screened by the rheumatologist or nurse and will be stored in the underlying data base. Clinical data that are collected during regular F2F-appointments will be stored together with the PROs according to a specific period of time.

Results: The datanetwork Rheuma 4.0 (DNR_4.0) is an association of 5 internistic-rheumatologic specialized practices.

By the automated documentation of PROs (patient) and medical measures (rheumatologist) in an underlying data base, scientific and health care real worl data can be collected without extra workload or time requirements. These data are specific and different from data collected by other centres. In principal, the extension of the group to increase the number of participating centres is easily possible because the interface is an "open system". This allows to build an automised collecting, big and representative data base.

Now pooled data sets of 18.000 patients are available in the data base. In a first step, quality and the completeness of the existing data sets will be evaluated and the daily documentation routines will be described. Anonymised statistical analysis of the pooled data sets of the rheumatologic centres will allow to gain knowledge in respect to health care research of the own working group and external interested parties like research groups, sick funds, insurance companies and companies.

Conclusions: The german biologic registry Rabbit and the "Core documentation" data base deliver valid data about the safety and efficacy of rheumatologic medication. The datanetwork Rheuma 4.0 will make a valuable contribution especially in conjunction with apps of patient's self management like RheumaLive and AxSpALive - to health care research, therapeutic strategies and clinical questions from daily practice.

Acknowledgements: RheumaLive and AxSpALive werde developed by Starhealth $\mathrm{GmbH}$ on behalf of UCB Pharma $\mathrm{GmbH}$.

Disclosure of Interest: S. Kleinert Speakers bureau: UCB, F. Schuch Speakers bureau: UCB, S. Späthling-Mestekemper Speakers bureau: UCB, M. Feuchtenberger Speakers bureau: UCB, C. Kuhn: None declared, M. Welcker Speakers bureau: UCB

DOI: 10.1136/annrheumdis-2017-eular.5674

\section{AB1113 PATIENT PARTICIPATION IS CRUCIAL WHEN INTRODUCING NEW DEVICE TECHNOLOGIES IN THE MANAGEMENT OF CHRONIC ARTHRITIS: APPLYING THE PARKER MODEL, A QUALITATIVE 3-STEP APPROACH}

T.S. Jørgensen ${ }^{1}$, L. Klokker ${ }^{1}$, M. Skougaard ${ }^{1}$, H. Asmussen ${ }^{2,3}$, A. Lee ${ }^{4}$, I. Mountian ${ }^{5}$, H. Gudbergsen ${ }^{1}$, L.E. Kristensen ${ }^{1} .{ }^{1}$ The Parker Institute, Copenhagen University Hospital, Bispebjerg and Frederiksberg, Copenhagen; ${ }^{2}$ Communication IKH, Roskilde University, Roskilde; ${ }^{3}$ NATiON, Copenhagen; ${ }^{4}$ University of Southern Denmark, Odense, Denmark; ${ }^{5}$ UCB Pharma, Brussels, Belgium

Background: Patients' participation in design, development, and implementation of new device technologies is essential to ensure added value in patients' disease management.

Objectives: To explore the applicability and relevance of ava ${ }^{\circledR}$, an electromechanical device (e-Device), as an alternative method for subcutaneous administration of certolizumab pegol.

Methods: The Parker Model is an innovative 3-step qualitative research approach, which combined concept mapping (CM), participatory design (PD), and stakeholder evaluation (SE) to evaluate the e-Device (Figure). CM was applied through workshops, with the participation of patients, using a structured group process focusing on relevant themes to identify issues and concerns with the e-Device. Patients used this information in a series of iterative PD sessions; patients participated in 3 interactive sessions to create a personal e-Device prototype in 
cooperation with a designer and a medical expert. This was followed by a common group session. Finally, SE was performed based on semi-structured group and individual interviews with patients and disease-management stakeholders.

Results: The study included 9 rheumatoid arthritis (RA) patients, 4 psoriatic arthritis (PsA) patients, 1 ankylosing spondylitis (AS) patient, 2 doctors, 2 nurses, 1 medical secretary, and 4 key public servants involved in the disease management of the selected rheumatic diseases. Saturation was reached after $3 \mathrm{CM}$ patient workshops, generating 121 statements, which were organized by the participants into themes. Through content analysis of the results from the 3 workshops, 4 concepts were generated: technical usability, physical design, concerns, and enthusiasm. These data were used in the iterative PD sessions, resulting in 4 new proposed prototypes. Finally, SE demonstrated that the identified concepts were pivotal for both facilitating and hampering device implementation, thus creating value when introducing the new e-Device.

Figure: The Parker Model

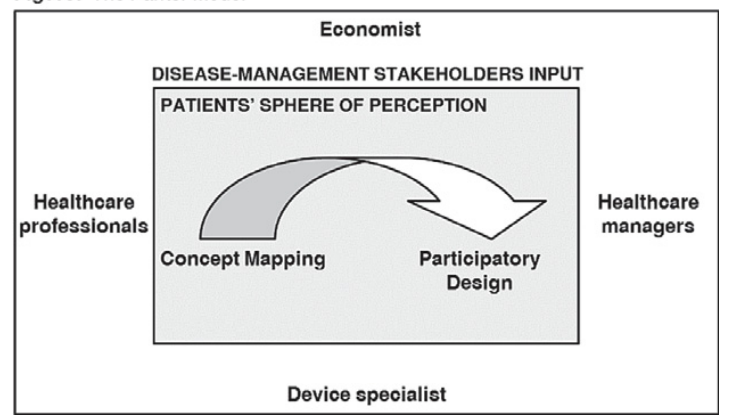

Conclusions: Patient participation in the 3-step qualitative Parker Model identified important aspects to consider when designing and implementing an innovative device for the treatment and management of RA, PSA, and AS. This is the first time a composite, qualitative research model has been applied when introducing a new device to support these disease areas. The responses from patients and disease-management stakeholders indicated that it is key to include patient input in the design and adaptation of devices alongside education and communication with stakeholders. These resources can help ensure added value when developing devices for the management of RA, PsA, and AS using biologic medicines.

Acknowledgements: This study was funded by UCB Pharma and the Oak Foundation. We thank the patients and their caregivers in addition to the investigators and their teams who contributed to this study. Editorial services were provided by Costello Medical Consulting.

Disclosure of Interest: T. Jørgensen Speakers bureau: Abbvie, Biogen, Novartis, Roche, UCB Pharma, L. Klokker: None declared, M. Skougaard: None declared, H. Asmussen Consultant for: The Parker Institute, UCB Pharma, A. Lee: None declared, I. Mountian Employee of: UCB Pharma, H. Gudbergsen: None declared, L. Kristensen Speakers bureau: AbbVie, Amgen, BMS, Celgene, Eli Lilly, Janssen Pharmaceuticals, MSD, Novartis, Pfizer, UCB Pharma DOI: 10.1136/annrheumdis-2017-eular.1770

\section{AB1114 PATIENT'S SELF-MONITORING OF DISEASE ACTIVITY OF RHEUMATIC DISEASES VIA WEBAPP - STUDY DESIGN, PATIENT'S PERSPECTIVE AND RECRUITMENT IN THE FIRST 11 MONTHS OF THE SWISS MULTICENTRE, LONGITUDINAL COMPASS II STUDY}

V.K. Jaeger ${ }^{1}$, P. Schiffer ${ }^{2}$, P. Zufferey ${ }^{3}$, L. Pichler ${ }^{1}$, A. Badaracco ${ }^{4}$, M. Walder ${ }^{5}$ ${ }^{\text {J. Dudler }}{ }^{6}$, D. Frey ${ }^{7}$, F. Müller ${ }^{1}$, U.A. Walker ${ }^{1} .{ }^{1}$ University Hospital Basel, Basel; ${ }^{2}$ Praxis beim Rathaus, Zofingen; ${ }^{3}$ Lausanne University Hospital, Lausanne; ${ }^{4}$ Studio Medico Badaracco Cattaneo, Lugano; ${ }^{5}$ Praxis Walder, Dübendorf; ${ }^{6}$ Hôpital Cantonal Fribourg, Fribourg; ${ }^{7}$ Praxis Frey, Basel, Switzerland

Background: The management of patients with rheumatic diseases is guided in part by asking patients about their medical history at each clinic visit. Patients often find it difficult to accurately remember the course of their symptoms between these appointments as they are often months apart. Regular app-based patients' self-monitoring of disease activity (with our without feedback to the rheumatologist) between clinic visits might provide a possible solution for this. The COmPASS I study [1] demonstrated that RA patients' self-assessments of disease activity via App correlate strongly with rheumatologists' assessments. Following up on this, the Swiss based COmPASS II study is embedded in the Swiss rheumatology registry (SCQM) and hence allows the linkage of data obtained via the COmPASS II App from the patients with routine clinical data collected in the registry.

The main aims of the COmPASS II study are to assess if continuous selfmonitoring of the disease by patients optimises disease management and outcome in rheumatic diseases, and to assess the fluctuation of disease activity between clinic visits.

Objectives: The objectives of this abstract are to describe the set-up and the recruitment of the COmPASS II study in the first 11 months.

Methods: The COmPASS II App questionnaire consists of the RAPID3 score, a validated, commonly used PRO to self-assess disease activity. Additionally, patients are asked about their therapy compliance and cortisone dose.

At inclusion, interested patients with RA, axSpA and PsA are electronically randomized into 3 study arms (Figure 1). In arm 1 patients and rheumatologist are displayed the self-assessed disease activity over time, the patient directly via the App and the rheumatologist via the SCQM registry. In arm 2 only the patients are displayed their disease activity chart and in study arm 3 neither sees the recorded data. Patients are encouraged to fill in the App weekly.

Results: The COmPASS II App went online on the 15/02/2016. In the first 11 months of COmPASS II, 272 patients were enrolled by their rheumatologist. $64 \%$ of patients used the WebApp (32\% in arm 1,38\% in arm 2 and $30 \%$ in arm 3); $82 \%$ of patients filled in the questionnaires for longer than a months, the longest follow-up was 11 months. On average patients use the App every 2 weeks. Patients found the App easy to use "The COmPASS II WebApp is so easy to use. It doesn't even take me 2 min." and received feedback included "Now my rheumatologist sees how I was since the last appointment instead of me trying to remember how I was half a year ago."

Figure 1. Design of the COmPASS II study.

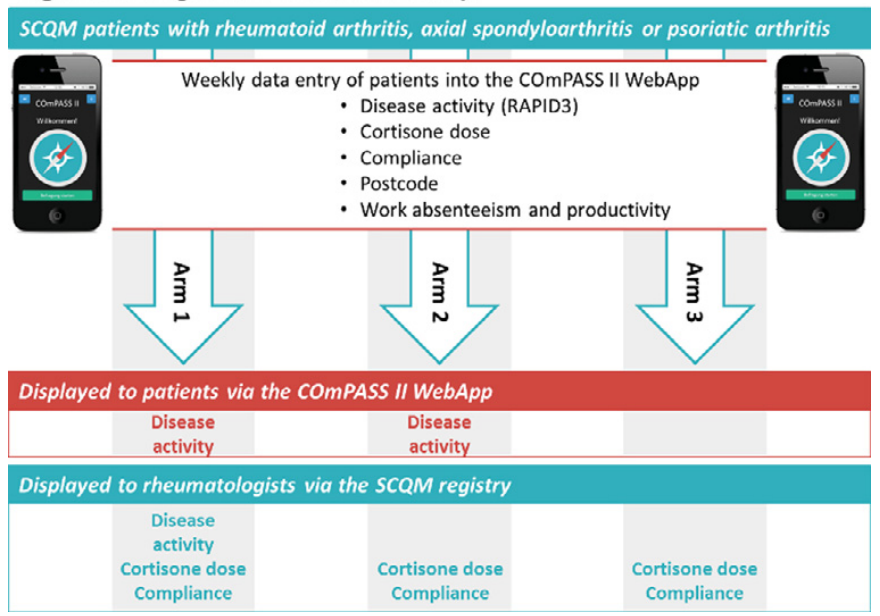

Conclusions: The COmPASS II study will validate the utility of app-based patients' self-assessments in enhancing disease control in a treat to target approach and deliver numerous additional scientific data.

References:

[1] Mueller R et al. Patient's Self-Monitoring Via Smartphone: The Compass Study - COrrelation between PAtient self-ASSessment of rheumatoid arthritis disease activity via smartphone technology and physicians' validated scores [abstract]. Arthritis Rheumatol. 2014;66(S10).

Acknowledgements: COmPASS II is supported by an unrestricted grant from AbbVie.

Disclosure of Interest: None declared

DOI: 10.1136/annrheumdis-2017-eular.3260

\section{AB1115 THE FEASIBILITY OF UTILIZATION OF MOBILE DEVICES TO ENHANCE PATIENT REPORTED OUTCOMES MEASURES (PROMS) IN RHEUMATOLOGY PRACTICE}

V. Ognenovski ${ }^{1}, 2$, K. Burger ${ }^{3}$, K. Weiss ${ }^{4}$, L. Esser ${ }^{4}$, D. Khanna ${ }^{1} .{ }^{1}$ Division of Rheumatology, University of Michigan, Ann Arbor, United States; ${ }^{2}$ Rheumatology Clinic, Ss Cyril and Methodius Faculty of Medicine, Skopje, Macedonia, The Former Yugoslav Republic Of; ${ }^{3}$ Information Technology; ${ }^{4}$ University of Michigan, Ann Arbor, United States

Background: Patient reported outcome measures (PROMs) are accepted modalities of gathering patient-reported health status such as physical, mental and social well-being. In addition to research applications, in some countries such as the United States, some of these measures are being considered as metrics for quality of care. The advent and wide spread use of the electronic medical record (EMR) in the United States has enabled providers (and patients) to collect PROMs electronically via patient portals (1).

At the University of Michigan, the patient medical record is maintained by MiChart- an EPIC ${ }^{\circledR}$ software which interfaces with the Patient Reported Outcomes Measures System -PROMIS (2)- an NIH funded project for development of assessment tools for collecting and analyzing patient health status. Our initial effort focused on integrating the PROMIS questionnaires into the patient EMR for two domains: Adult Physical Function and Pain Intensity Scores into patient portals (electronic patient-physician communication tool), thus enabling patient to complete questionnaires from home computers. Our collection rate of completed PROMs questionnaires via patient portals was about $5-10 \%$.

Objectives: The aim of our project was to examine/enhance collection rate of PROMs with the utilization of portable devices /tablet based PROMs at the time of check-in the clinic by the patient. 